\title{
Tindakan Pencegahan Pembakaran Hutan dalam Perspektif ASEAN Community
}

\begin{tabular}{|c|c|}
\hline \multicolumn{2}{|r|}{$\begin{array}{l}\text { Retno Kusniati }^{1} \text {, Bunga Permatasari }{ }^{1 *} \text {, Mohamad Rapik } \\
{ }^{1} \text { Fakultas Hukum, Universitas Jambi, 36361, Jambi-Indonesia }\end{array}$} \\
\hline Info Artikel & ABSTRAK \\
\hline $\begin{array}{l}\text { Dikirim: Okt 25, } 2020 \\
\text { Diterima: Jan } 18,2021 \\
\text { Dipublikasi: Jan } 31,2021 \\
\end{array}$ & $\begin{array}{l}\text { Abstract This article aims to elaborate on the values of the ASEAN Community in } \\
\text { preventing forest and land fires through the ASEAN Agreement Transboundary Haze } \\
\text { Pollution (AATHP), and the Implementation of AATHP in Indonesia. This is because the }\end{array}$ \\
\hline $\begin{array}{l}\text { Kata Kunci: } \\
\text { ASEAN; } \\
\text { Hutan; } \\
\text { Lahan; } \\
\text { Pembakaran; }\end{array}$ & $\begin{array}{l}\text { causes cross-border air pollution which results in disruption of diplomatic relations } \\
\text { among the ASEAN Member States. Even though ASEAN Member countries have agreed to } \\
\text { create an ASEAN Community. Therefore, by applying the normative juridical legal } \\
\text { research method, this paper intends to explore several things, namely first; how the values } \\
\text { of the ASEAN Community in preventing forest and land fires through the ASEAN }\end{array}$ \\
\hline $\begin{array}{l}\text { Koresponden: } \\
\text { Bunga Permatasari } \\
\text { Fakultas Hukum } \\
\text { Universitas Jambi }\end{array}$ & $\begin{array}{l}\text { of AATHP in Indonesia. This article finds that the values of the ASEAN Community have } \\
\text { been contained in every article regulated in the AATHP for the prevention of forest and } \\
\text { land fires that occur in the ASEAN region. Second, Indonesia has ratified the AATHP and } \\
\text { made legal products that can reach actors of forest and land burning. This is marked by } \\
\text { the passing of the Law on Environmental Protection and Management, the Forestry Law, } \\
\text { the Plantation Law, and the Law on Prevention and Eradication of Forest Destruction. } \\
\text { Besides, in Jambi Province, Jambi Province has also established Local Regulation } \\
\text { Number } 2 \text { of } 2016 \text { concerning Prevention and Control of Forest and Land Fires. }\end{array}$ \\
\hline
\end{tabular}

\section{Sitasi Cantuman:}

Kusniati, R., Permatasari, B., \& Rapik, M. (2021). Tindakan Pencegahan Pembakaran Hutan dalam Perspektif ASEAN Community. Journal of Political Issues. 2(2); 115 123.

https://doi.org/10.33019/jpi.v $2 \mathrm{i} 2.37$

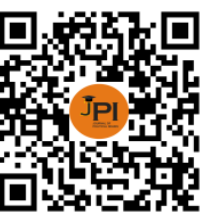

DOI:

https://doi.org/10.33019/jpi.v $2 \mathrm{i} 2.37$

Lisensi:

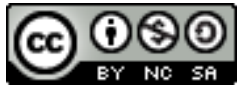

Attribution-NonCommercialShareAlike 4.0 International (CC- BY-NC-SA 4.0)

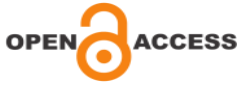

Abstrak Artikel ini bertujuan untuk memaparkan tentang nilai-nilai ASEAN Community dalam pencegahan pembakaran hutan dan lahan melalui ASEAN Agreement Transboundary Haze Pollution (AATHP), dan Implementasi AATHP di Indonesia. Hal ini disebabkan karena Persoalan Kebakaran hutan dan Lahan merupakan salah satu isu utama di kawasan ASEAN, dan dampaknya menimbulkan pencemaran udara lintas batas negara yang mengakibatkan terganggunya hubungan diplomatik diantara Negara Anggota ASEAN. Padahal negara Anggota ASEAN bersepakat untuk mewujudkan ASEAN Community. Oleh karena itu, dengan menerapkan metode penelitian hukum yuridis normatif, tulisan ini hendak menjelajahi beberapa hal, yaitu pertama; bagaimana nilai-nilai nilai-nilai ASEAN Community dalam pencegahan pembakaran hutan dan lahan melalui AATHP, Kedua, bagaimana implementasi AATHP di Indonesia. Artikel ini menemukan bahwa nilai-nilai ASEAN Community telah tertuang dalam setiap pasal yang diatur dalam AATHP guna pencegahan kebakaran hutan dan lahan yang terjadi pada kawasan ASEAN, Kedua, Indonesia telah meratifikasi AATHP dan membuat produk hukum yang dapat menjangkau para pelaku pembakaran hutan dan lahan. Hal ini ditandai dengan disahkannya UU Perlindungan dan Pengelolaan Lingkungan Hidup, UU Kehutanan, UU Perkebunan, dan UU Pencegahan dan Pemberantasan Perusakan Hutan. Selain itu, di Provinsi Jambi, juga membentuk Peraturan Daerah Provinsi Jambi Nomor 2 Tahun 2016 tentang Pencegahan Dan Pengendalian Kebakaran Hutan Dan Lahan.

\section{Tentang:}

Retno Kusniati, menyelesaikan studi Magister (S2) Universitas Sriwijaya pada tahun 2004. Saat ini penulis adalah mahasiswa Program Pascasarjana Doktor Ilmu Hukum Universitas Jambi dan dosen Fakultas Hukum di Universitas Jambi.

Bunga Permatasari, menyelesaikan studi Magister (S2) Universitas Jambi pada tahun 2014. Saat ini penulis adalah dosen Fakultas Hukum di Universitas Jambi

Mohamad Rapik, menyelesaikan studi Magister (S2) pada dua Institusi yaitu IAIN Sultan Thaha Saifudin Jambi pada tahun 2003 dan Universitas Jambi pada tahun 2012. Saat ini penulis adalah mahasiswa Program Pascasarjana Doktor Ilmu Hukum Universitas Jambi dan dosen Fakultas Hukum di Universitas Jambi. 


\section{PENDAHULUAN}

Hutan adalah anugerah tak ternilai dari Tuhan. Oleh karena itu manusia memiliki tanggung jawab untuk melindungi dan melestarikannya dengan antara lain menghindari menyebabkan kerusakan di bumi ini agar tidak hanya dilestarikan untuk hari ini tetapi juga di masa depan (Gusliana,2019). Peristiwa bencana El Nino yang mengakibatkan hangusnya hutan seluas 25 juta hektar (ha) di seluruh dunia, membuat isu lingkungan terkait kebakaran hutan menarik perhatian International (Tacconi, 2003).

Kebakaran hutan dan lahan merupakan ancaman bagi pembangunan berkelanjutan karena dampaknya secara langsung terhadap ekosistem(UNISDR 2002), kebakaran tersebut, berkontribusi terhadap peningkatan emisi karbon yang memicu perubahan iklim dan berdampak pada produktivitas dan mengancam keanekaragaman hayati (Sommers, Loehman, \& Hardy, 2014).

Di Asia Tenggara, permasalahan mengenai dampak kebakaran hutan mendapat perhatian yang serius dengan disepakatinya Agreement on Transboundary Haze Pollution (AATHP) untuk mencegah dan menanggulangi pencemaran asap lintas-batas oleh negara anggota ASEAN. Selain itu, dalam kerja sama ASEAN di bidang lingkungan hidup, salah satu focus utamanya adalah penyelesaian kabut asap lintas batas negara (Yudha dkk, 2017).

Indonesia pernah menjadi sorotan dunia tahun 1997-1998 akibat kebakaran hutan dan lahan yang terjadi cukup lama. Negara Asean terutama Thailand, Filipina, dengan Malaysia dan Singapura yang paling terpengaruh akibat asap dari kebakaran hutan dan lahan tersebut (Schweithelm, \& Barber, 2000). Kebakaran besar hutan dan lahan terulang kembali di 2015 dan 2019. laporan dari Lembaga Penerbangan dan Antariksa Nasional memperkirakan luas hutan dan lahan Indonesia yang terbakar Tahun 2015 mencapai 2.089.911 hektar (ha) yang terdiri dari 618.574 ha lahan gambut dan 1.471.337 (ha) lahan non gambut. Selain itu, Bank Dunia mencatat total kerugian yang diakibatkan bencana kabut asap itu mencapai Rp 221 triliun (Tempo, 2016).

Shannon N Koplitz mengemukakan ada 100.300 kasus kematian yang disebabkan oleh kebakaran hutan di Indonesia pada September-Oktober 2015. Dari jumlah itu diperkirakan 91.600 (24.000-159.200) di Indonesia, 6.500 (1.700-11.300) di Malaysia, dan 2200 (660-3.800) di Singapura (Koplitz, dkk., 2016). Berbeda dengan yang disampaikan oleh Kepala Pusat Data dan Informasi dan Humas Badan Nasional Penanggulangan Bencana (BNPB) Sutopo Purwo Nugroho, ada sebanyak 24 orang yang meninggal dunia akibat peristiwa kebakaran hutan dan lahan tersebut (Putri, 2015).

Tahun 2019 peristiwa kebakaran hutan dan lahan pun kembali terulang. Bukan Indonesia saja yang mengalami kebakaran hutan dan lahan yang besar, melainkan beberapa Negara di ASEAN pun juga turut terbakar hutannya. Di Thailand, Kebakaran telah menghancurkan hutan sebanyak 2.7 juta rai yang berada di 9 Provinsi Thailand Utara (The Thaiger, 2019)' Selain itu, diberitakan bahwa asap kebakaran hutan dan lahan Indonesia telah menyebar hingga ke Thailand Selatan (Perdana, 2019) dan kawasan resort Phuket (Asmardika, 2019).

Kebakaran hutan dan lahan ini dipicu oleh kebiasaan masyarakat dan para pemegang perkebunan menggunakan metode slash and burn (Potter, Padoch, \& Peluso, 1996) dalam membuka lahan. Selain itu, aktivitas ini juga dilakukan dalam rangka transformasi pembukaan lahan transmigrasi (Schweithelm, \& Barber, 2000), industri perkebunan dan palawija (Barr, 2001), dan lahan perkebunan ke kelapa sawit (Schweithelm, \& Barber, 2000). Menurut Kemen G Austin, Amanda Schwantes, Yaofeng Gu, dan Prasad S Kasibhatla menunjukkan bahwa ekspansi perkebunan kelapa sawit dari tahun 2001-2016 menyebabkan hilangnya 23 persen hilangnya tutupan hutan Indonesia (Virgy, Djuyandi, \& Darmawan, 2020). Selain itu, Under Fire (Greenpeace Indonesia, 2015) yang dikeluarkan pada November 2015 menyebutkan perusahaan-perusahaan pemasok minyak kelapa sawit Wilmar International melakukan deforestasi melalui metode pembakaran lahan hutan dan 
menyebabkan dampak kesehatan yang masif terhadap masyarakat sekitar (Virgy, Djuyandi, \& Darmawan, 2020).

Kenyataannya, berdasarkan hukum internasional, pencemaran udara lintas batas negara akibat kebakaran hutan dan lahan akan menjadi tanggung negara sebagaimana ditegaskan dalam Prinsip 21 Deklarasi Stockholm 1972 bahwa:

"States have, in accordance with the Charter of the United Nations and the principles of international law, the sovereign right to exploit their own resources pursuant to their own environmental policies, and the responsibility to ensure that activities within their jurisdiction or control do not cause damage to the environment of other States or of areas beyond the limits of national jurisdiction."

Di sisi ini lain terkait pula dengan prinsip "Sic Utere Tuo Alienum Non Laedas (Seseorang harus menggunakan miliknya dengan tidak menimbulkan kerugian terhadap orang lain)"(Triadmodjo, 2000) yang menentukan bahwa "No state has the right to use or permit the use of its territory in such a manner as to cause injury by fumes in or to the territory of another and that measures of control were necessary"(Kamil, 1999)

Pasal 2 huruf (a) Undang-Undang Nomor 32 Tahun 2009 tentang Pengelolaan dan Perlindungan Lingkungan Hidup (UUPLH) mengatur bahwa Perlindungan dan pengelolaan lingkungan hidup dilaksanakan berdasarkan asas tanggung jawab Negara. Provinsi Jambi, turut bertanggung jawab dalam pencemaran udara akibat kebakaran hutan dan lahan. Berdasarkan Data Warsi, terdapat 30.947 titik api. 157.137 (ha) hutan dan lahan di Jambi terbakar, yang mana hutan 101.418 (ha) merupakan hutan gambut. Dan ini lebih buruk dari tahun 2015, 90.363 hutan gambut yang terbakar serta kerugian lingkungan 12 triliun rupiah (Suprapto \& Suryadi, 2020).

Padahal Hutan Gambut di Provinsi Jambi mempunyai nilai penting bagi dunia, karena mampu menyimpan setidaknya 57 miliar ton karbon. dan Kawasan hutan gambut yang terbakar, salah satunya ada di kawasan Taman Nasional Berbak yang merupakan kawasan pelestarian alam untuk konservasi hutan rawa terluas di Asia Tenggara.

Kewajiban untuk mengambil langkah pencegahan dan penanggulangan diatur dalam Pasal 3 ayat (3) AATHP bahwa:

"The Parties should take precautionary measures to anticipate, prevent and monitor tranboundary haze pollution as a result of land and/or forest fires which should be mitigated, to minimise its adverse effects. Where there are threats of serious or irreversible damage from transboundary haze pollution, even without full scientific certainty, precautionary measures shall be taken by Parties concerned."

Kewajiban tersebut ditegaskan kembali dalam ketentuan Pasal 4 bahwa:

"When the transboundary haze pollution originates from within their territories, respond promptly to a request for relevant information or consultations sought by a State or States that are or may be affected by such transboundary haze pollution, with a view to minimising the consequences of the transboundary haze pollution. Take legislative, administrative and/or other measures to implement their obligations under this Agreement."

Kebakaran hutan dan lahan yang berakibat pada pencemaran udara lintas batas negara tersebut tentunya akan menghalangi tujuan dari pembentukan ASEAN Community. Masyarakat ASEAN yang secara resmi diberlakukan pada tanggal 31 Desember 2015 memiliki tujuan tidak hanya mempertahankan stabilitas keamanan kawasan dan meningkatkan kesejahteraan rakyat, tetapi sekaligus mendorong terciptanya masyarakat yang berpandangan maju, hidup dalam lingkungan yang damai, stabil, sejahtera, demokratis serta 
saling peduli dan melindungi hak asasi dan keadilan sosial (Direktorat Jenderal Kerjasama ASEAN, 2018).

Oleh karena itu, berdasarkan persoalan yang ditimbulkan oleh pencemaran udara lintas batas negara yang terjadi di ASEAN akibat kebakaran hutan dan lahan, artikel ini berupaya menelusuri bagaimana nilai-nilai ASEAN Community dalam pencegahan pembakaran hutan dan lahan dalam AATHP, Kedua, bagaimana implementasi AATHP di Indonesia.

\section{METODE PENELITIAN}

Artikel ini menggunakan metode penelitian yuridis normatif. Adapun pendekatan yang dilakukan meliputi pendekatan perundang-undangan, pendekatan konseptual, dan pendekatan analitis (Sinamo, 2009). Pengumpulan dan Penelusuran bahan-bahan hukum yang relevan menggunakan sistem mendeley. Bahan hukum terkumpul diindentifikasi dengan cara studi bahan-bahan hukum dan studi dokumen yang relevan. Bahan hukum hakekat, asas-asas, konsepsi-konsepsi, doktrin hukum serta substansi norma hukum dalam pencegahan dan penanggulangan kebakaran hutan dan lahan dikumpulkkan melalui referensi yang bersifat:1) umum yaitu buku hukum, dan review hukum dan internasional, dan 2) khusus berupa jurnal hukum. Studi dokumen merujuk dan dilakukan pada dokumen public yang resmi dan terpecaya.

\section{HASIL PENELITIAN DAN PEMBAHASAN}

\section{Upaya Pencegahan Pembakaran Hutan Dan Lahan Dalam Perspektif nilai-nilai ASEAN Community.}

ASEAN Charter (Piagam ASEAN) telah ditetapkan sebagai statuta dasar ASEAN menggantikan Deklarasi ASEAN. Perubahan ini berakibat secara de jure ASEAN menjadi organisasi kawasan yang berdasarkan aturan (Puspita, 2015). Selain itu, ASEAN juga membentuk ASEAN Community. ASEAN Community ini dibentuk dengan tiga pilar utama. Ketiga pilar tersebut Mayarakat Sosial Budaya ASEAN, Masyarakat Ekonomi ASEAN, dan Masyarakat Keamanan ASEAN. Dari ketiga pilar tersebut, Masyarakat Sosial Budaya ASEAN yang merupakan salah satu pilar ditandai eksistensinya melalui cetak biru masyarakat Sosial Budaya ASEAN yang memiliki karakterisitik atau nilai yaitu: engages and benefits people, inclusive, sustainable, resilient, dynamic.(Direktorat Jenderal Kerjasama ASEAN, 2018)

Jauh sebelum disahkannya ASEAN Community tersebut, nilai-nilai Masyarakat Sosial Budaya ASEAN yang berupa engages and benefits people, inclusive, sustainable, resilient, dynamic (Direktorat Jenderal Kerjasama ASEAN, 2018) dapat ditemukan semangat nilai tersebut dalam AATHP. Kebakaran Hutan dan Lahan yang terjadi di Indonesia dan Negara anggota ASEAN merupakan salah satu tantangan yang dihadapi masyarakat Sosial budaya ASEAN sejak sebelum ASEAN community terbentuk. Dan AATHP merupakan salah satu cara yang ditempuh oleh negara anggota ASEAN guna memperkuat kerja sama kawasan dalam pengelolaan hutan secara berkelanjutan dalam konteks pencegahan dan pengendalian kebakaran hutan yang dapat menyebabkan pencemaran udara lintas batas Negara melalui Penandatanganan AATHP. Meskipun tiap-tiap negara ASEAN memiliki respon yang berbeda-beda dalam meratifikasi AATHP tesebut. Hal ini dapat terlihat dalam tabel di bawah. 
Table 1 Negara Yang Telah Meratifikasi AATHP

\begin{tabular}{ccc}
\hline Negara Anggota & Tanggal Ratifikasi & $\begin{array}{c}\text { Tanggal Penyerahan } \\
\text { Ratifikasi }\end{array}$ \\
\hline Brunei Darussalam & 27 Febuari 2003 & 23 April 2003 \\
Kamboja & 24 April 2006 & 9 November 2006 \\
Filipina & 1 Febuari 2010 & 4 Maret 2010 \\
Myanmar & 5 Maret 2003 & 17 Maret 2003 \\
Thailand & 10 September 2003 & 26 September 2003 \\
Myanmar & 5 Maret 2003 & 17 Maret 2003 \\
Laos & 19 Desember 2004 & 13 Juli 2005 \\
Indonesia & 16 September 2014 & 20 Januari 2015 \\
Malaysia & 3 Desember 2002 & 18 Febuari 2003 \\
Vietnam & 24 Maret 2003 & 29 Mei 2003 \\
\hline
\end{tabular}

Sumber: ASEAN Haze Action, 2015

Pada intinya, nilai-nilai ASEAN yang terdapat AATHP merupakan wujud nyata sense of community. Sense of Community didefinisikan sebagai "a feeling that members have of belonging, a feeling that members matter to one another and to the group, and a shared faith that members' needs will be met through their commitment to be together" (McMillan \& Chavis, 1986) yang dapat diartikan rasa kebersamaan adalah perasaan yang dimiliki anggota, perasaan bahwa anggota itu penting satu sama lain dan untuk kelompok, dan keyakinan bersama bahwa kebutuhan anggota akan terpenuhi komitmen mereka untuk bersama.

Untuk itu sense of community dari ASEAN Community mempunyai motto ASEAN: One Vision, One Identity, One Community. Oleh karenanya, motto ASEAN tersebut membuat Keberadaan AATHP sebagai dasar hukum yang digunakan oleh semua anggota ASEAN untuk membuat produk hukum dalam pencegahan dan penanggulangan kebakaran hutan di negaranya, agar memperkuat secara bersama-sama dalam kedaulatan negara masing-masing untuk menindak kasus kebakaran hutan dan lahan secara tegas. Selain hal tersebut, AATHP juga memperkokoh hubungan kerjasama regional dan internasional dalam hal percepatan penanganan kebakaran hutan dan lahan.

Terdapat 32 Pasal secara keseluruhan dalam AATHP. Adapun 32 Pasal ini terdiri dari:

a. Ketentuan Umum

Pasal 1-4 dalam Bab I Ketentuan Umum ini pada dasarnya berisi tentang definisi dari istilah-istilah yang digunakan, tujuan, prinsip, dan kewajiban umum yang ada dalam AATHP.

b. Pemantauan, Penilaian, Pencegahan, dan Tanggapan.

Pasal 5-15 dalam Bab II mengatur bahwa tiap anggota ASEAN harus benar siap dalam melaksanakan aktivitas pemantauan, penilaian, pencegahan, dan tanggapan saat terjadi kebakaran hutan dan lahan di negaranya yang berpotensi dapat menyebabkan pencemaran udara lintas batas Negara.

c. Kerja Sama Teknis dan Penelitian Ilmiah

Pasal 16 dan 17 dalam Bab III mengatur tentang kerja sama teknis dan penelitian ilmiah antara Anggota dan ASEAN Centre yang mana ASEAN Centre harus memfasilitasi aktifitas kerja sama teknis guna melaksanakan proses pencegahan dan penaggulangan pencemaran udara lintas batas Negara akibat dari kebakaran hutan dan lahan.

d. Pengaturan Kelembagaan

Pasal 18 - Pasal 20 bab IV berisikan tentang pengaturan kelembagaan

e. Prosedur 
Pasal 21 - Pasal 27 mengatur tentang prosedur dan keuangan untuk pengendalian pencemaran udara lintas batas negara akibat kebakaran hutan dan lahan harus melalui hasil mufakat.

f. Ketentuan Akhir

Pasal 28-31 merupakan Bab ketentuan akhir dalam Perjanjian internasional ini.

\section{Implementasi ASEAN Agreement Transboundary Haze Pollution di Indonesia.}

Indonesia telah meratifikasi AATHP melalui Undang-Undang Nomor 26 Tahun 2014, guna mengatasi pencemaran asap lintas batas secara efekif yang diakibatkan oleh Kebakaran Hutan dan Lahan. Hal ini demi tercapainya tujuan Masyarakat Sosial Budaya ASEAN.

Perjanjian ini berisi mengenai ketentuan dalam pengawasan, penilaian dan pencegahan, kerjasama teknis, dan penelitian ilmiah, mekanisme dalam koordinasi, jalur komunikasi dan penyederhanaan prosedur imigrasi bagi penanggulangan bencana. Berdasarkan perjanjian ini, maka didirikan ASEAN Coordinating Center for Transboundary Haze Pollution Control yang bertujuan untuk menangani berbagai aktivitas yang harus dilaksanakan menurut perjanjian (Hakim, 2007)

Indonesia, sebagai bentuk komitmen dalam mematuhi isi dari Pasal 9 AATHP, membentuk produk hukum nasional dalam rangka penindakan hukum terhadap tindakan pidana pelaku pembakaran hutan dan lahan. Hal ini dibuktikan dengan disahkannya UU Perlindungan dan Pengelolaan Lingkungan Hidup (UUPPLH), UU Kehutanan, UU Perkebunan, dan UU Pencegahan dan Pemberantasan Perusakan Hutan. UUPPLH yang dalam isinya terdapat pengaturan larangan pembukaan lahan dengan cara pembakaran hutan, maka diberikan sanksi berupa pidana penjara dan denda.

Di sisi yang berbeda, pengaturan tentang sanksi terhadap orang yang membakar hutan diatur dengan Undang-Undang Kehutanan. Selain itu, UU Perkebunanan mengatur bahwa setiap para pemilik Pelaku Usaha Perkebunan, terdapat larangan untuk membuka dan/atau mengolah lahan dengan cara membakar. Jika tindakan ini dilakukan, maka akan ada sanksi pidana penjara dan denda.

Selanjutnya, Peraturan Menteri dan Presiden terkait isu kebakaran hutan dan/atau lahan yang berpedoman pada aturan AATHP adalah Peraturan Menteri Lingkungan Hidup dan Kehutanan RI No: P.74/menlhk/setjen/kum.1/8/2016 tentang Pedoman Nomenklatur Perangkat Daerah Provinsi dan Kabupaten/Kota Urusan Pemerintah Bidang Lingkungan Hidup dan Kehutanan. Peraturan ini merupakan bentuk tindak lanjut dari amanah Pasal 211 ayat (2) Undang-Undang Nomor 23 Tahun 2014 tentang Pemerintah Daerah dan pasal 109 ayat (1) PP Nomor 18 Tahun 2016 tentang perangkat daerah.

Berdasarkan Peraturan Menteri Lingkungan Hidup dan Kehutanan ini, pemerintah daerah akan menetapkan stuktur organisasi, tata hubungan kerja, tugas dan fungsi dari Dinas Lingkungan Hidup dan Kehutanan yang ditetapkan melalui Peraturan Gubernur dan Peraturan Walikota. Jadi setiap daerah diamanatkan tugas untuk membuat sistem regulasi pemanfaatan hutan, yang mana hal ini sesuai dengan yang diinginkan oleh AATHP agar negara anggota membuat regulasi tentang pemanfaatan hutan yang melibatkan berbagai pihak yang dianggap perlu, salah satunya pemerintahan daerah.

Provinsi Jambi yang merupakan kesatuan dari Negara Indonesia, wajib turut serta mewujudkan tujuan dari masyarakat Sosial Budaya ASEAN, karena merupakan bagian dari masyarakat ASEAN itu sendiri. Salah satu caranya dengan mencegah terjadi kebakaran hutan dan lahan di Provinsi Jambi, yang dampaknya tidak hanya dirasakan oleh masyarakat di Provinsi Jambi, namun dapat dirasakan seluruh Masyarakat ASEAN, terutama dampak dari pencemaran udara lintas batas negara akibat kebakaran hutan dan lahan yang terjadi. Oleh karenanya, dibentuklah Peraturan Daerah Provinsi (PERDA) Jambi Nomor 2 Tahun 2016 tentang Pencegahan Dan Pengendalian Kebakaran Hutan Dan Lahan. 
PERDA Provinsi Jambi ini pada dasarnya mengatur larangan bagi setiap orang/badan hukum untuk membakar hutan dan lahan guna membuka hutan/lahan tersebut. Selain itu, terdapat pula pengaturan sanksi hukum administrasi terhadap pemegang izin jika dalam pengawasan ditemukan pelanggaran terkait pencegahan dan pengendalian kebakaran hutan dan lahan. Setiap orang atau pemegang izin yang dengan sengaja dan/atau karena kelalaiannya menyebabkan terjadinya pencemaran dan kerusakan lingkungan akibat kebakaran hutan dan lahan diancam dengan pidana sesuai peraturan perundang-undangan.

Keberlakuan PERDA Provinsi Jambi Nomor 2 Tahun 2016 tentang Pencegahan Dan Pengendalian Kebakaran Hutan Dan Lahan menunjukan bahwa Indonesia telah memiliki produk hukum terkait pencegahan kebakaran hutan dan lahan di tingkat nasional dan juga di tingkat lokal, dan hal tersebut membuktikan bahwa adanya keinginan kuat Indonesia untuk berkomitmen dan tunduk terhadap AATHP, Meskipun Indonesia belum memiliki aturan khusus yang mengatur tentang pencemaran kabut asap lintas batas negara.

Persoalan yang muncul dalam rangka menanggulangi pencemaran asap lintas batas, AATHP mengembangkan kebijakan pembukaan lahan tanpa bakar (zero burning policy) yang diatur dalam Pasal 9 ayat (1). Sayangnya, ketentuan ini bertentangan dengan beberapa peraturan perundang-undangan yang ada di Indonesia. Padahal seharusnya ada harmonisasi ketentuan dalam perundang-undangan dengan ketentuan dalam AATHP. Adapun Peraturan perundang-undangan yang bertentangan tersebut terdapat Pada Pasal 69 ayat 2 UUPPLH: "Ketentuan sebagaimana dimaksud pada ayat (1) huruf h memperhatikan dengan sungguhsungguh kearifan lokal di daerah masing-masing."

Penjelasan umum UUPPLH ini menyatakan kearifan lokal yang dimaksud adalah melakukan pembakaran lahan dengan luas lahan maksimal 2 hektar per kepala keluarga untuk ditanami tanaman jenis varietas lokal dan dikelilingi oleh sekat bakar sebagai pencegah penjalaran api ke wilayah sekelilingnya. Hal ini didukung pula dengan adanya Peraturan Menteri Negara Lingkungan Hidup Nomor 10 Tahun 2010 tentang Mekanisme Pencegahan Pencemaran dan/atau Kerusakan Lingkungan Hidup yang Berkaitan dengan Kebakaran Hutan dan/ atau Lahan, menurut Permen ini, masyarakat hukum adat diperbolehkan untuk melakukan pembakaran lahan dengan luas lahan maksimum 2 (dua) hektar per kepala keluarga untuk ditanami jenis varietas lokal.

\section{SIMPULAN}

Salah satu langkah yang ditempuh guna pencegahan terjadinya kebakaran dan lahan di Indonesia yaitu dengan Indonesia meratifikasi AATHP. AATHP merupakan perjanjian yang dibentuk oleh negara Anggota ASEAN, hal ini dikarenakan ASEAN memiliki motto One Vision, One Identity, One Community. Oleh karenanya, motto ASEAN tersebut membuat Keberadaan AATHP sebagai dasar hukum yang digunakan oleh semua anggota ASEAN untuk membuat produk hukum dalam pencegahan dan penanggulangan kebakaran hutan di negaranya, agar memperkuat secara bersama-sama dalam kedaulatan negara masing-masing untuk menindak kasus kebakaran hutan dan lahan secara tegas. adapun salah satu langkah yang dilakukan Indonesia dalam implementasi AATHP adalah dengan membuat peraturan perundangan-undangan yang berkaitan dalam pencegahan terjadinya kebakaran hutan dan lahan. Hal ini ditandai dengan disahkannya UU Perlindungan dan Pengelolaan Lingkungan Hidup, UU Kehutanan, UU Perkebunan, dan UU Pencegahan dan Pemberantasan Perusakan Hutan. Selain itu, di Provinsi Jambi, juga membentuk Peraturan Daerah Provinsi Jambi Nomor 2 Tahun 2016 tentang Pencegahan Dan Pengendalian Kebakaran Hutan Dan Lahan. 


\section{DAFTAR PUSTAKA}

ASEAN Haze Action. (2015, September 17). Status of Ratification. ASEAN Haze Action Online. http://haze.asean.org/status-of-ratification/ (August 20, 2020).

Asmardika, R. (2019). "Kabut Asap Dari Indonesia Capai Thailand, Selimuti Resor Wisata Di Phuket." okezone.com. https://news.okezone.com/read/2019/09/23/18/2108192/kabut-asap-dari-indonesiacapai-thailand-selimuti-resor-wisata-di-phuket (August 17, 2020).

Barr, Christopher M. \& Center for International Forestry Research. \& World Wide Fund for Nature. Macroeconomics for sustainable Development Program Office. (2001). Banking on sustainability : structural adjustment and forestry reform in post-Suharto Indonesia /by Christopher Barr. Washington, D.C : WWF Macroeconomics Program Office

Direktorat Jenderal Kerjasama ASEAN. (2018). ASEAN Selayang Pandang, 23rd ed. Jakarta: Direktorat Jenderal Kerjasama ASEAN

Gusliana, H. B. (2019). The Authority of the Local Government in Forest Management and its Implication toward Local Autonomy in Riau Province. Jambe Law Journal, 1(2), 251-267. https://doi.org/10.22437/jlj.1.2.251-267

Hakim, Fika Yulialdina. 2007. "International Law Making ASEAN Agreement on Transboundary Haze Pollution." Indonesia Journal of International Law 4(4): 816-30.

Kamil, M. (1999). Prinsip-Prinsip dalam Hukum Lingkungan Internasional. Jurnal Hukum \& Pembangunan, 29(2), 107. https://doi.org/10.21143/jhp.vol29.no2.553

Koplitz, S. N., Mickley, L. J., Marlier, M. E., Buonocore, J. J., Kim, P. S., Liu, T., Sulprizio, M. P., DeFries, R. S., Jacob, D. J., Schwartz, J., Pongsiri, M., \& Myers, S. S. (2016). Public health impacts of the severe haze in Equatorial Asia in September-October 2015: demonstration of a new framework for informing fire management strategies to reduce downwind smoke exposure. Environmental Research Letters, 11(9), 094023. https://doi.org/10.1088/1748-9326/11/9/094023

McMillan, D. W., \& Chavis, D. M.. (1986). "Sense of Community: A Definition and Theory." Journal of Community Psychology 14(1): 6-23.

Perdana, A. V. (2019). "Kabut Asap Selimuti Langit Di Thailand Selatan, Disebut Akibat Karhutla Di Indonesia." Kompas.com. https://internasional.kompas.com/read/2019/09/23/19282121/kabut-asap-selimuti-langitdi-thailand-selatan-disebut-akibat-karhutla?page=all (August 17, 2020).

Potter, L., Padoch, C., \& Peluso, N. L. (January 01, 1996). Forest degradation, deforestation, and reforestation in Kalimantan: Towards a sustainable land use?. Borneo in Transition : People, Forests, Conservation, and Development, 13-40.

Puspita, N. Y. (2015). KEWENANGAN HUKUM ASEAN DALAM MEMBUAT PERJANJIAN INTERNASIONAL DENGAN PIHAK EKSTERNAL BERDASARKAN PIAGAM ASEAN. Yustisia Jurnal Hukum,4(3), 719-745. 
https://doi.org/10.20961/yustisia.v4i3.8704

Putri, W. D. (2015, December 20). BNPB Catat Kerugian Akibat Kebakaran Hutan 2015 Rp $221 \quad$ Triliun. Republika Online. https://nasional.republika.co.id/berita/nasional/umum/15/12/20/nzms82359-bnpb-catatkerugian-akibat-kebakaran-hutan-2015-rp-221-triliun (February 17, 2020).

Schweithelm, J., \& Barber, C. V. (2000). Trial by Fire : Forest Fires and Forestry Policy in Indonesia's Era of Crisis and Reform. Washington: World Resources Inst.

Sinamo, N. (2009). Metode Penelitian Hukum. Jakarta: PT. Bumi Intitama Sejahtera

Sommers, W. T., Loehman, R. A., \& Hardy, C. C. (2014). Wildland fire emissions, carbon, and climate: Science overview and knowledge needs. Forest Ecology and Management, 317, 1-8. https://doi.org/10.1016/j.foreco.2013.12.014

Suprapto, Y., \& Suryadi. 2020. "Mengulas Karhutla Jambi 2019, Awal Tahun Riau Mulai Kebakaran.” Mongabay. https://www.mongabay.co.id/2020/01/27/mengulas-karhutlajambi-2019-awal-tahun-riau-mulai-kebakaran/ (February 17, 2020).

Tacconi, L. (2003). Kebakaran hutan di Indonesia: penyebab, biaya dan implikasi kebijakan. Kebakaran Hutan Di Indonesia: Penyebab, Biaya Dan Implikasi Kebijakan, 1-28. https://doi.org/10.17528/cifor/001200

Tempo. (2016). "Riset: Ada 100.300 Kematian Akibat Kebakaran Hutan 2015." tempo.co. https://nasional.tempo.co/read/805612/riset-ada-100-300-kematian-akibat-kebakaranhutan-2015?page_num=1 (February 17, 2020).

The Thaiger. (2019, April 13). Forest fires destroy 2.7 million rai of land whilst Chiang Mai is back on top. https://thethaiger.com/hot-news/air-pollution/forest-fires-destroy-2-7million-rai-of-land-whilst-chiang-mai-is-back-on-top (February 17, 2019).

Triadmodjo, M. (2000). "Anatomi Hukum Lingkungan International: Sistem Generik Penyangga Kehidupan Ummat Manusia." Jurnal i-lib UGM 2: 128-42. http://ilib.ugm.ac.id/jurnal/download.php?dataId=2415.

UNISDR. 2002. "Disaster Reduction and Sustainable Development Disaster Reduction and Sustainable Development Understanding the Links between Vulnerability and Risk to Disasters Related to Development and Environment.” In , 3. www.unisdr.org.

Virgy, M. A., Djuyandi, Y., \& Darmawan, W. B. (2020). Strategi Jaringan Advokasi Transnasional Greenpeace Indonesia Terkait Isu Deforestasi Hutan Indonesia oleh Wilmar International. Journal of Political Issues, 1(2), 74-91. https://doi.org/10.33019/jpi.v1i2.9

Yudha, W., Chandra, M., Petranto, A., J.S. Lantu, G., and Siahaan, B. Y. P. (2017). Satu Visi Satu Identitas Satu Masyarakat. 22nd ed. Jakarta: Sekretariat Direktorat Jenderal Kerja Sama ASEAN, Ditjen Kerja Sama ASEAN, Kementerian Luar Negeri. 